\title{
Detection of electromagnetic anomalies of three earthquakes in Mexico with an improved statistical method
}

\author{
O. Chavez ${ }^{1}$, R. Pérez-Enríquez ${ }^{2}$, J. A. Cruz-Abeyro ${ }^{2}$, J. R. Millan-Almaraz ${ }^{1}$, A. Kotsarenko ${ }^{2}$, and E. Rojas ${ }^{1}$ \\ ${ }^{1}$ División de Investigación y Posgrado, Facultad de Ingeniería, Universidad Autónoma de Querétaro, Centro Universitario, \\ Cerro de las Campanas s/n, Querétaro, Querétaro, C.P. 76010, México \\ ${ }^{2}$ Centro de Geociencias (CGEO), Juriquilla, UNAM, Apdo Postal 1-742, Centro Querétaro, Querétaro, México, \\ C.P. 76001, México
}

Received: 22 March 2011 - Revised: 25 May 2011 - Accepted: 26 May 2011 - Published: 21 July 2011

\begin{abstract}
A method for detecting seismomagnetic signals is presented. This work presents evidence of geomagnetic perturbations associated with three earthquakes (EQs) that occurred in Mexico within a distance of $\rho=(1.8) 10^{0.45 \mathrm{M}}$, where $\mathrm{M}$ is the magnitude of the EQ, during the year 2010 . An improved statistical analysis in relation with the polarization analysis (as the ratio of vertical magnetic field component to the horizontal one) has been developed. The variation index $\left(\mathrm{S}_{4}\right)$ shows important differences one day before and one day after the EQs (magnitudes considered are from 6 to 7.2).
\end{abstract}

\section{Introduction}

Evidence of electromagnetic emission at several frequencies associated with EQs has been accumulated over the years (e.g., Hayakawa and Molchanov, 2002; Molchanov and Hayakawa, 2008). The presence of strong interferences hampers the accumulation of the experimental data to test existing ideas on the mechano-electromagnetic conversion in the Earth's crust (Guglielmi et al., 2006). In addition, many authors perform the signal processing in a wide frequency ranges reporting geomagnetic perturbations related to EQs. Such anomalies have been reported for several decades (Parrot and Johnston, 1989; Johnston, 1997; Kushwah et al., 2009; Telesca and Hattori, 2007; Telesca et al., 2008). Seismogenic phenomena in the ULF (ultra low frequency) range, with frequency from 0.005 to $1 \mathrm{~Hz}$ (Kopytenko et al., 1993) related with EQs has been studied since Fraser-Smith et al. (1990) and a number of papers have been published on this topic after that (Smirnova et al., 2004; Serita et al., 2005;

Correspondence to: $\mathrm{O}$. Chavez

(omar.chavez@uaq.mx)
Kushwah et al., 2009). This frequency range is of practical importance in relation with EQ activity, since these waves are able to propagate easily on the Earth's surface where a ULF sensor is installed (Ida et al., 2008).

The serious problem regarding these seismogenic ULF emissions is the detection of these weak signals. Different methods of analysis have been developed: polarization analysis by means of the ratio of vertical magnetic field component to the horizontal (Hayakawa et al., 1996), fractal analysis (mono- and multi-) (Hayakawa et al., 1999; Gotoh et al., 2004; Smirnova et al., 2004; Ida et al., 2005; Ida and Hayakawa, 2006; Kotsarenko et al., 2004, 2005, 2007), principal component analysis (Gotoh et al., 2002; Hattori et al., 2004; Kotsarenko et al., 2005), and singular value decomposition (Hattori et al., 2006), among others.

All the aforementioned methods are applied to improve both the detection of the ULF signals associated with seismogenic phenomena at different frequencies (Hayakawa et al., 2008), and the understanding of electromagnetic phenomena associated with tectonic and volcanic activity (Currenti et al., 2005a, b). In this paper, a simple polarization analysis which is the simplest analysis method has been used. But we have looked into the problem variation in order to improve the statistical method. This improved polarizations statistical method was applied to the ULF data observed in Mexico during the year 2010. We found a significant correlation in the data obtained for three EQs in Mexico near the observing station, within the earthquake radius preparation zone $(\rho)$, as a modification of the previously stated equation proposed by Dobrovolsky et al. (1979) and Dobrobolsky (1993b), where $\rho=(1.8) 10^{0.45 \mathrm{M}}$, where $\mathrm{M}$ is the magnitude of the EQ (Fig. 1). Finally, the results obtained in this paper would be compared with earlier results obtained with the wavelet method (Chavez et al., 2010).

Published by Copernicus Publications on behalf of the European Geosciences Union. 


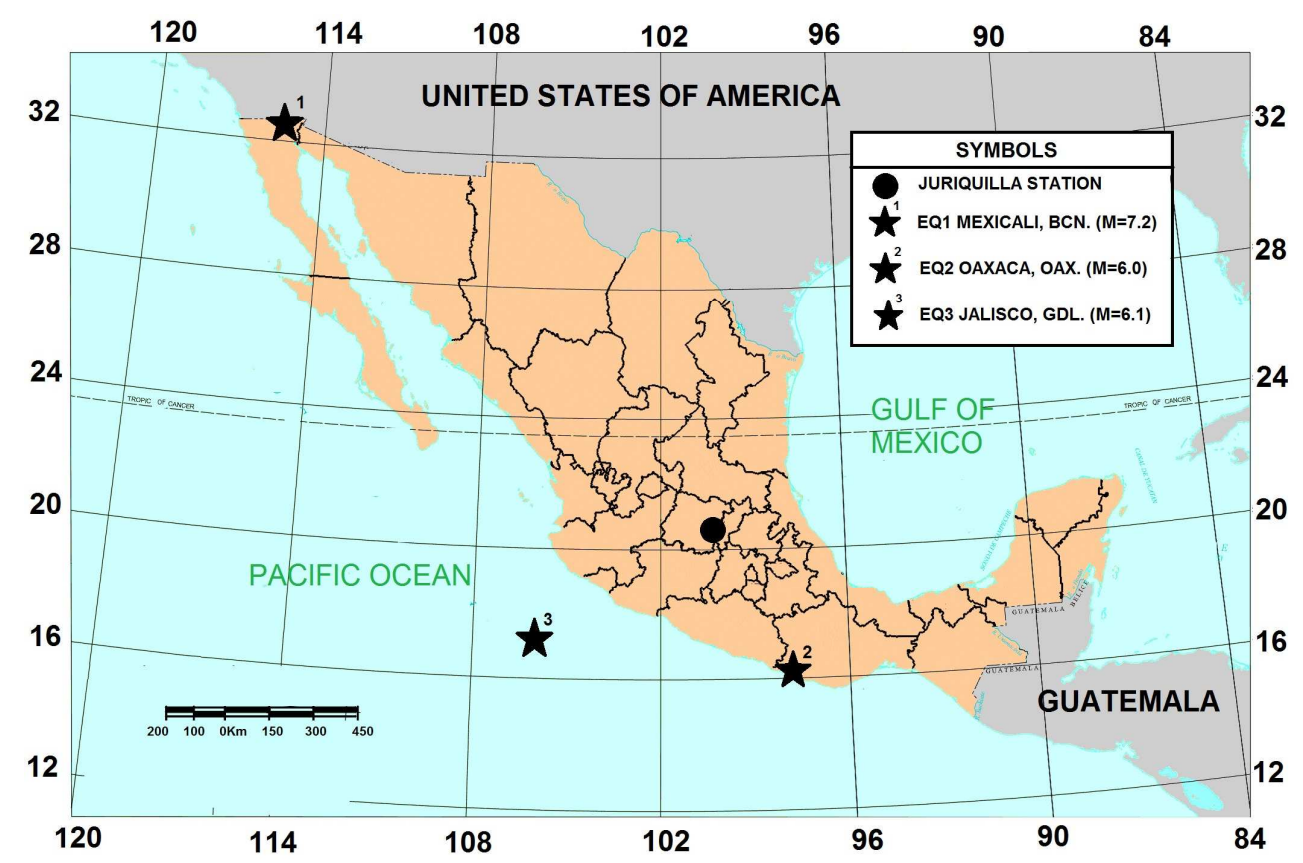

Fig. 1. The relative location of the geomagnetic observatory, Juriquilla (JU2) and three EQs (indicated by black stars) occurring during the year 2010 .

\section{ULF geomagnetic data and EQs}

ULF geomagnetic data is obtained at an observatory named Juriquilla (JU2) (geographic coordinates: $-100.45^{\circ} \mathrm{N}$, $20.70^{\circ} \mathrm{E}$ ) as in Fig. 1. At this field site we observe three geomagnetic components ( $H$ : N-S component, $D$ : E-W component, and $Z$ : vertical component) by means of fluxgate sensors. The sampling frequency is $1 \mathrm{~Hz}$. The analysis focused on three rather big EQs (with magnitude greater than 6.0) within a distance to the station of $\rho=(1.8) 10^{0.45 \mathrm{M}}$, where $\mathrm{M}$ is the magnitude of the EQ. All the events occurred during the year 2010. The first EQ took place on 4 April, the second on 30 June, and the third on 10 August. The characteristics of the EQs are presented in Table 1. The distance between the EQs and the geomagnetic observatory is consistent with that considered in a previous study (Chavez et al., 2010). In such study the perturbations associated with the magnitude of the EQs could be observed.

\section{Signal analysis}

The polarization method developed by Hayakawa et al. (1996) is based on the measurement of the ratio of spectral power of the vertical magnetic field $(Z)$ to the horizontal magnetic fields $(H$ and $D$ ) (i.e., $Z / H$ or $Z / D$ ). This ratio is known to provide information of related variations of the geomagnetic field of ionospheric origin (or solar-terrestrial effect) or seismic origin (Ida et al., 2008). Generally speaking, the polarization ratio becomes larger when there are seis- mogenic emissions (Ida et al., 2008), while the geomagnetic field variation are found to show smaller values (Hayakawa et al., 1996),

The time series of the ULF data was processed to obtain the polarization signals $Z / H$ and $Z / D$ from the three geomagnetic components $H, D$, and $Z$ as was previously reported by Ida et al. (2008). Furthermore, the Fast Fourier Transform (FFT) is performed to the polarization signals to obtain the power spectrum. Figure 2 shows three ratio signals corresponding to the FFT spectra of each one of the three seismic events. This was performed in order to analyze the components of the frequency previously associated to seismogenic ULF emissions (Hayakawa et al., 2007). It can be observed that FFT spectrum is not adequate to show significant differences or common patterns between the three FFT spectra. For that reason, a Discrete Wavelet Transform (DWT) analysis was used to analyze the three ratio signals. This type of analysis was selected due to its time-frequency decomposition capabilities. This methodology has been previously reported for co-seismic event detection in $H, D$, and $Z$ components (Chavez et al., 2010). For this study, six DWT levels were analyzed using a wavelet mother function Daubechies 1 (DB1), but we present only the D6 for comparative reasons (see Fig. 2). Table 2 shows the frequency bands corresponding to each DWT analysis level for signals that were sampled at a frequency of $1 \mathrm{~Hz}$. The first event is presented in blue, the second in red, and the third in green (see Table 1).. Some frequency activity can be inferred from highest observable amplitude during the D6 level of the DWT decomposition at 
Table 1. Earthquakes occurring in Mexico during 2010 (magnitude greater than 6) selected for this analysis. Year/month/day/hour/min are: the exact time of the EQ (Local Time); Latitude and Longitude: the geographic coordinates of the epicenter; Magnitudes and Depth: magnitude and depth of the EQ; Distance: the distance between the epicenter and Juriquilla station; $\rho$ : the radius of the EQ preparation zone estimated by the proposed equation. The EQ magnitudes are presented in bold.

\begin{tabular}{|c|c|c|c|c|c|c|c|c|c|c|c|c|}
\hline Event & Year & Month & Day & Hour & Min & Longitude & Latitude & Magnitude, M & Depth, km & Distance, $\mathrm{km}$ & $\rho, \mathrm{km}$ & Distance/ $\rho$ \\
\hline 1 & 2010 & 4 & 4 & 17 & 40 & -115.36 & 32.54 & 7.2 & 10 & 1974 & 2245 & 0.87 \\
\hline 2 & 2010 & 6 & 30 & 2 & 22 & -98.03 & 16.22 & 6.0 & 8 & 563 & 684 & 0.82 \\
\hline 3 & 2010 & 8 & 23 & 21 & 11 & -107.23 & 18.44 & 6.1 & 10 & 751 & 755 & 1.00 \\
\hline
\end{tabular}
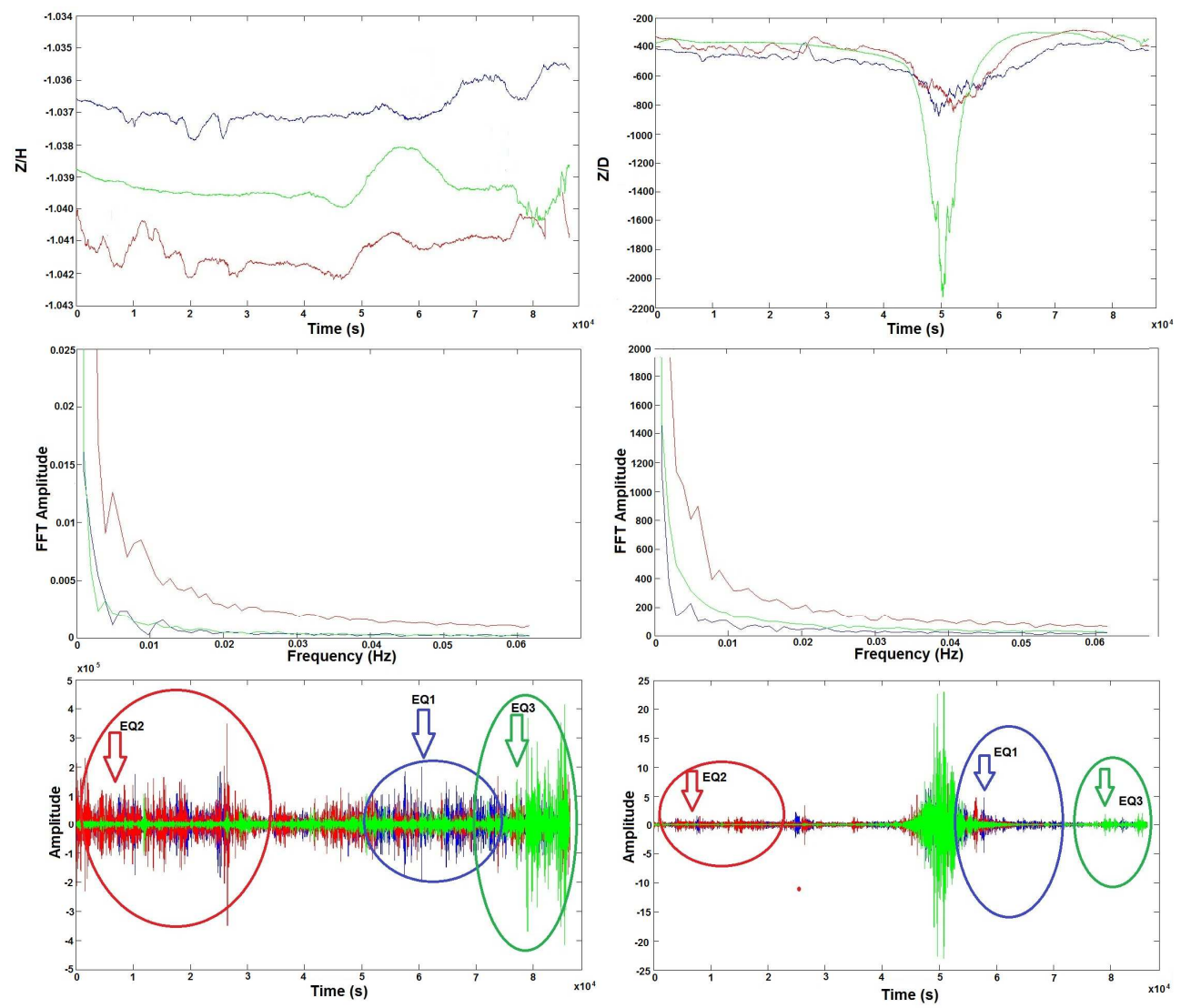

Fig. 2. Geomagnetic data analyzed: The first event is presented in blue, the second in red, and the third in green. The FFT analysis does not show important peaks. Included is a Discrete Wavelet Transform (DWT) of the $Z / H$ and $Z / D$ ratio in a superposed analysis in the ULF frequency range $f=0.0078125$ to $0.015625 \mathrm{~Hz}$. The main seismic shocks are shown with arrows.

the start of the signals followed by amplitude suppression periods. The aforementioned behaviour is common to the three analyzed seismic events. There are some important peaks during the EQs in different frequency ranges, e.g., for the three EQs we have significant increases from the D2 to the D6 $(0.0078125-0.25 \mathrm{~Hz})$. Those results can be associated with the distance and the magnitude of the EQs.

Furthermore, Fig. 2 also shows the corresponding DWT decomposition for the signals $Z / D$ ratio, where the middle cluster during the day is the principal perturbation. However it can be observed that important amplitudes in each level are present. The values of $Z / H$ and $Z / D$ are computed as representing the daily data. This process implies that the distance of analysis is directly associated to the magnitude of the EQ.

\section{Observation results}

An improved variation index method is proposed herein. The superposed epoch analysis was performed over the basis of 5 
Table 2. DWT decomposition bandwidths in $\mathrm{Hz}$ for a sampling frequency $f_{s}=1 \mathrm{~Hz}$.

\begin{tabular}{cll}
\hline Level & Approximation (An) & Detail (Dn) \\
\hline 1 & 0 to $0.25 \mathrm{~Hz}$ & 0.25 to $0.5 \mathrm{~Hz}$ \\
2 & 0 to $0.125 \mathrm{~Hz}$ & 0.125 to $0.25 \mathrm{~Hz}$ \\
3 & 0 to $0.0625 \mathrm{~Hz}$ & 0.0625 to $0.125 \mathrm{~Hz}$ \\
4 & 0 to $0.03125 \mathrm{~Hz}$ & 0.03125 to $0.0625 \mathrm{~Hz}$ \\
5 & 0 to $0.015625 \mathrm{~Hz}$ & 0.015625 to $0.03125 \mathrm{~Hz}$ \\
6 & 0 to $0.0078125 \mathrm{~Hz}$ & 0.0078125 to $0.015625 \mathrm{~Hz}$ \\
\hline
\end{tabular}
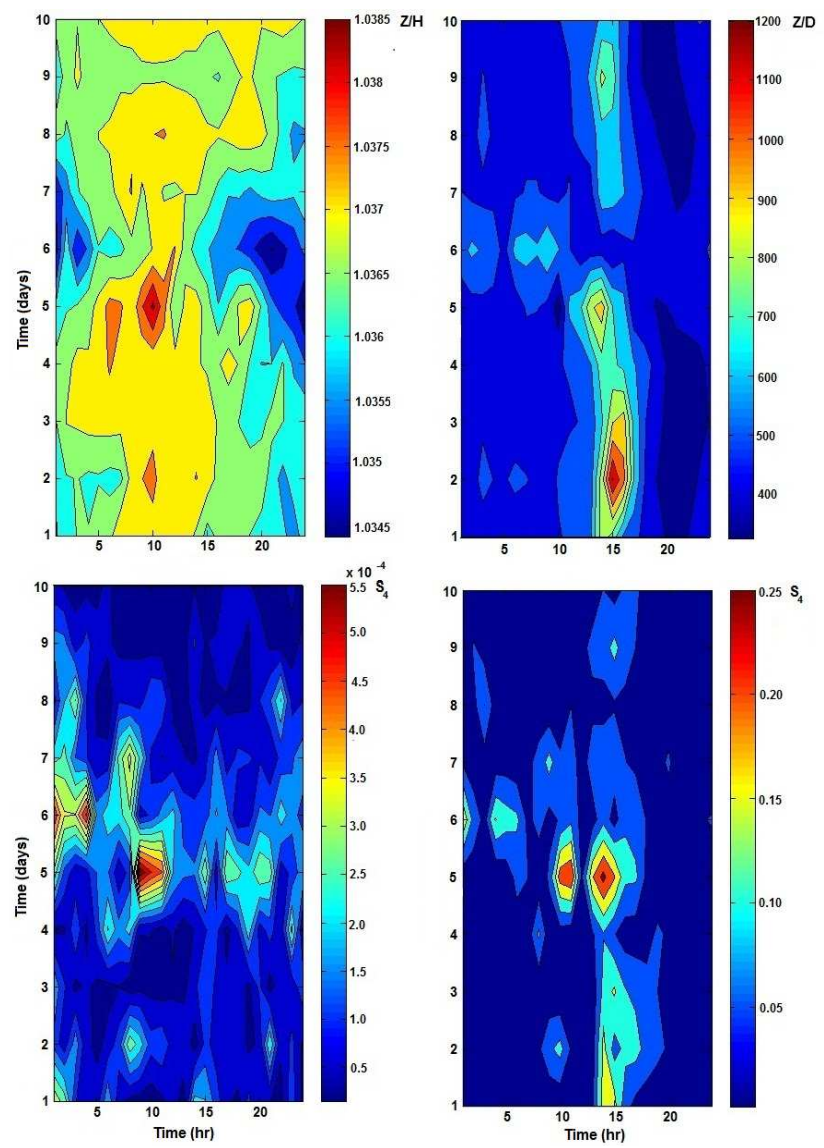

Fig. 3. Map showing the time series of the analysis for the first event $Z / H$ (top right), and $Z / D$ (top left). At the bottom, the variation index for $Z / H$ (left), and for $Z / D$ (right).

days before and 5 days after the EQ. The variation index is defined by,

$$
S_{4}=\frac{\sigma_{i}}{\bar{x}}
$$

where $S_{4}$ is the variation index considering a mean period of ten days and for the $i$ ratio $(i=Z / H$ and $Z / D), \bar{x}$ is the average of the component $i$ over the whole period, and $\sigma_{i}$ is
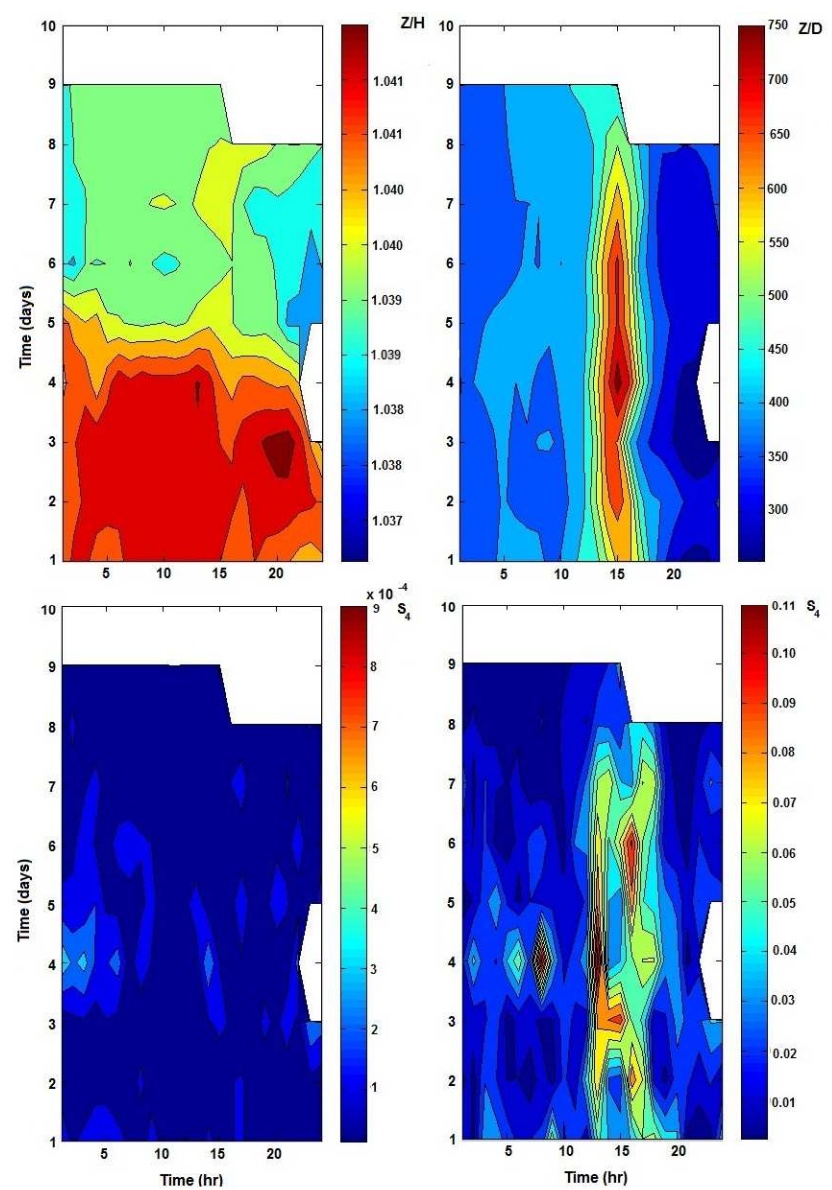

Fig. 4. Map showing the time series of the analysis for the first second event $Z / H$ and $Z / D$ top right and left, respectively. At the bottom, the variation index for $Z / H$ (left), and for $Z / D$ (right). There are no data in the white areas.

the standard deviation of the same component $i$ ratio over the whole period.

Figures 3, 4 and 5 illustrate the temporal evolution of the analysis $(Z / D$ and $Z / H)$ during the period of 5 days before and 5 days after the EQs (see Table 1). The day of each EQs occurrence is during the 5th day, and its specific time is shown in Table 1. Figure 3 shows the corresponding analysis (on top) and the variation index obtained for the first event. Important increments on the variation index are observed $7 \mathrm{~h}$ before and almost $12 \mathrm{~h}$ after the event. Also it is observed that these variations are observed only around day 5. Figure 4 shows this same analysis, but in this case the white areas indicate the periods where data could not be recorded due to some problems of the ULF system. However, $24 \mathrm{~h}$ before and $24 \mathrm{~h}$ after the main shock an important increase in the variation index was observed. The increment variation index is mainly associated to the $Z / D$ ratio. The $Z / H$ ratio has similar changes as those observed in Fig. 4, where a sudden decrease on this value previous 

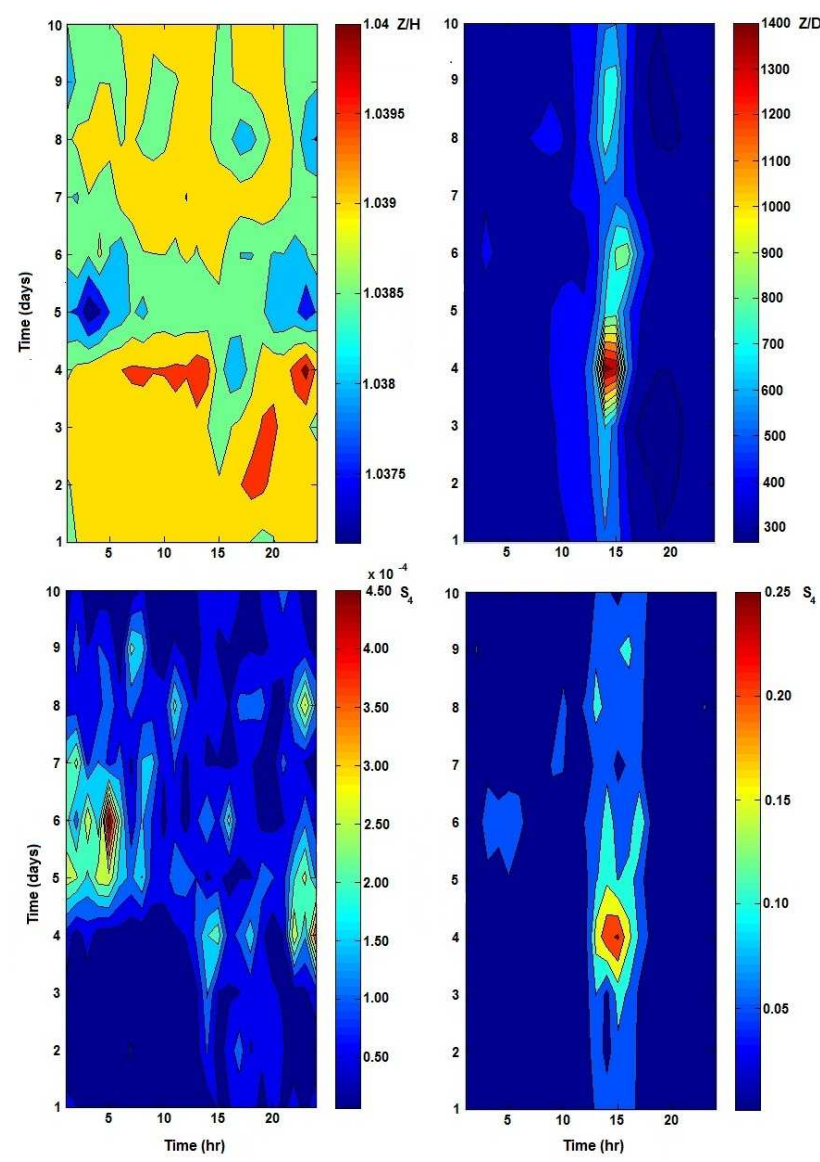

Fig. 5. Map showing the time series of: The analysis for the third event $Z / H$, and $Z / D$ top right and left, respectively. At the bottom, the variation index for $Z / H$ (left), and for $Z / D$ (right).

to the main shocks is shown. In the last figure, important increases in the variation index are observed almost $30 \mathrm{~h}$ before and $10 \mathrm{~h}$ after the EQ. Figure 6 shows certain enhancement in the $Z / H$ and $Z / D$ plots just before, during, and after the EQs and also shows significant increments in the variation index. The data was compared with the geomagnetic activity expressed by the Dst index (data obtained from http://wdc.kugi.kyoto-u.ac.jp/dstdir/) where those indices apparently had no correlation with EQs variation index (see Fig. 5).

The increase in the polarization and the variation index resulted not only from the increase in $Z / H$, but also from the increase and decrease of $Z / D$. These figures show a significant increase of the variation index occurs before, during, and after the EQs. The indices of Dst and Kp did not show important changes during this period. This indicates that the polarization and the statistical analysis are closely associated with occurrence of EQs. The three EQs analyzed exhibit significant changes.
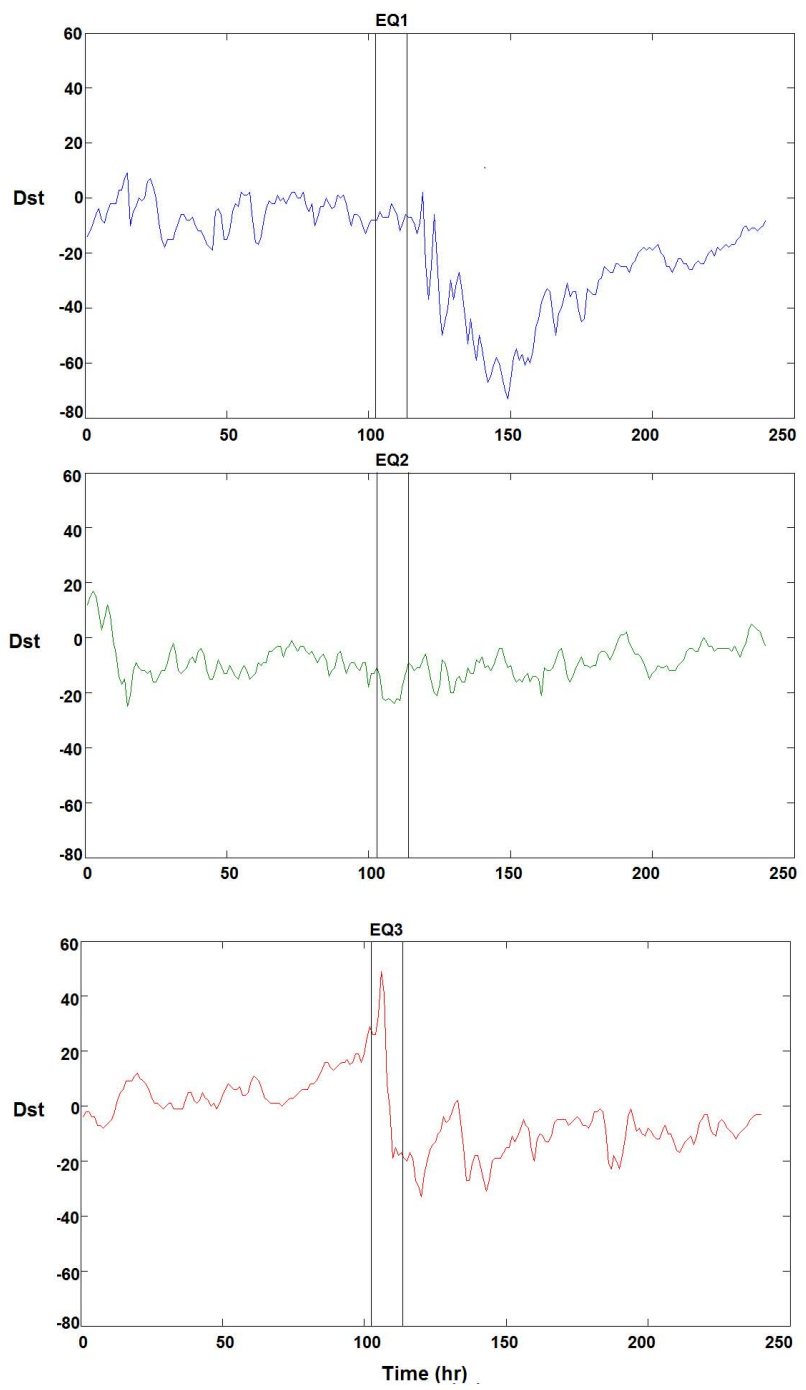

Fig. 6. Dst Index obtained from Kyoto observatory web page corresponding with the $3 \mathrm{EQs}$ analyzed. The period of time presented is 10 days.

\section{Conclusions}

There are seismo-magnetic signals related to EQs disturbing the electromagnetic field. The principal problem of the signal detection is the discrimination of the background noise. For that reason, the use of the DWT at different levels is proposed. Additionally, an improved statistical polarization analysis method has been applied to the ULF geomagnetic data at Juriquilla station in Mexico. The three geomagnetic field components recorded behave in different ways; for that reason a general variation index is used to estimate the perturbations for each polarization during the whole period. By using the variation index, it is found that the polarization ratio between the vertical and the horizontal magnetic field components $(Z / H, Z / D)$ at different levels (see Table 2) exhibits 
significant clusters during the day of analysis. An increase in the variation index value, with the maximum value a few hours before and after the EQs, are observed. The application of a DWT filter using different levels in order to obtain frequency components that correspond to associated seismic anomalies shows that there are not predetermined favorable frequency ranges - apparently it depends on the direction, the distance, and the magnitude of each EQ analyzed. This kind of ULF lead time seems to be consistent with a previous work by Chavez et al. (2010). The epicentral distance of these three superficial EQs varies from 563 to $1974 \mathrm{~km}$.

Acknowledgements. The authors are grateful to CONACyT and Centro de Geociencias of the National University of Mexico (UNAM) for their support and collaboration in this research under the project number 209837.

Edited by: M. E. Contadakis

Reviewed by: two anonymous referees

\section{References}

Chavez, O., Millan-Almaraz, J. R., Pérez-Enríquez, R., ArzateFlores, J. A., Kotsarenko, A., Cruz-Abeyro, J. A., and Rojas, E.: Detection of ULF geomagnetic signals associated with seismic events in Central Mexico using Discrete Wavelet Transform, Nat. Hazards Earth Syst. Sci., 10, 2557-2564, doi:10.5194/nhess-102557-2010, 2010.

Currenti, G., Del Negro, C., Lapenna, V., and Telesca, L.; Fluctuation analysis of the hourly time variability of volcano-magnetic signals recorded at Mt. Etna volcano, Sicily (Italy), Chaos Solitons \& Fractals, 23, 1921-1929, 2005a.

Currenti, C. Del Negro, C., Lapenna, V., and Telesca, L.: Scaling characteristics of local geomagnetic field and seismicity at Etna volcano and their dynamisc in relation to the eruptive activity, Earth Planet. Sci. Lett., 235, 96-106, 2005b.

Dobrovolsky, I. P., Zubkov, S. I., and Myachkin, V. I.: Estimation of the size of earthquake preparation zones, Pure Appl. Geophys., 117, 1025-1044, 1979.

Dobrovolsky, I. P.: Analysis of preparation of a strong tectonic earthquake, Phys. Solid Earth, 28, 481-492, 1993.

Fraser-Smith, A. C., Bernardi, A., McGill, P. R., Ladd, M. E., Helliwell, R. A., and Villard, O. G.: Low-frequency magnetic measurements near the epicenter of the Ms 7.1 Loma Prieta earthquake, Geophys. Res. Lett. 17, 1465-1468, 1990.

Guglielmi, A., Hayakawa, M., Potapov, A., and Tsegmed, B.: Polarization method to detect the co-seismic magnetic oscillations, Phys. Chem. Earth, 31, 299-304, 2006.

Gotoh, K., Akaniga, Y., Hayakawa, M., and Hattori, K.: Principal component analysis of ULF geomagnetic data for Izu islands earthquakes in July 2000, J. Atmos. Electr., 22, 1-12, 2002.

Gotoh, K., Hayakawa, M., Smirnova, N. A., and Hattori, K.: Fractal analysis of seismogenic ULF emissions, Phys. Chem. Earth, 29, 419-424, 2004.

Hattori, K., Serita, A., Gotoh, K., Yoshino C., Harada, M., Isezaki, N., and Hayakawa M.: ULF geomagnetic anomaly associated with 2000 Izu Islands earthquake swarm, Japan Physics and Chemistry of the Earth, Parts A/B/C, 29, 4-9, 425-435, 2004.
Hattori, K., Serita, A., Yoshino, C., Hayakawa, M., and Isezaki, N.; Singular spectral analysis and principal component analysis for signal discrimination of ULF geomagnetic data associated with 2000 Izu Island earthquake swarm, Phys. Chem. Earth, 31, 281291, 2006.

Hayakawa, M., Kawate, R., Molchanov, O. A., and Yumoto, K.: Results of ultra-low-frequency magnetic field measurements during the Guam earthquake of 8 August 1993, Geophys. Res. Lett., 26(18), 2797-2800, 1996.

Hayakawa, M., Ito, T., and Smirnova, N.: Fractal analysis of ULF geomagnetic data associated with the Guam earthquake on $8 \mathrm{Au}-$ gust 1993, Geophys. Res. Lett., 26, 18, 2797-2800, 1999.

Hayakawa, M. and Molchanov, O.: Seismo Electromagnetics Lithosphere-Atmosphere-Atmosphere-Ionosphere Coupling, TERRAPUB, Tokyo, Japan, 477, 2002.

Hayakawa, M., Hattori, K., and Ohta, K.: Monitoring of ULF (ultralow-frequency) geomagnetic variations associated with earthquakes, Sensors, 7, 1108-1122, 2007.

Hayakawa, M., Hattori, K., and Ohta, K.: Observation of ULF Geomagnetic Variations and Detection of ULF Emissions Associated with Earthquakes: Review, Electric Engineering in Japan, 162, 4, Traslated from Denki Gakkai Ronbunshi, 126-A, 12, December 2006, 1238-1244, 2008.

Ida, Y. and Hayakawa, M.: Fractal analysis for the ULF data during the 1993 Guam earthquake to study prefracture criticality, Nonlin. Processes Geophys., 13, 409-412, doi:10.5194/npg-13409-2006, 2006.

Ida, Y., Hayakawa, M., Adalev, A., and Gotoh, K.: Multifractal analysis for the ULF geomagnetic data during the 1993 Guam earthquake, Nonlin. Processes Geophys., 12, 157-162, doi:10.5194/npg-12-157-2005, 2005.

Ida, Y., Yang, D., Li, Q., Sun, H., and Hayakawa, M.: Detection of ULF electromagnetic emissions as a precursor to an earthquake in China with an improved polarization analysis, Nat. Hazards Earth Syst. Sci., 8, 775-777, doi:10.5194/nhess-8-7752008, 2008.

Johnston, M. J. S.: Review of electric and magnetic fields accompanying seismic and volcanic activity, Surv. Geophys., 18, 441475, 1997.

Kopytenko, Y. A., Matiashvili, T. G., Voronov, P. M., Kopytenko, E. A., and Molchanov, O. A.: Detection of ultra-low-frecuency emissions and its aftershock activity, based on geomagnetic pulsations data at Dusheti and Vardzia observatories, Phys. Earth Planet. In., 77, 85-95, 1993.

Kotsarenko, A., Pérez Enríquez, R., López Cruz-Abeyro, J. A., Koshevaya, S., Grimalsky, V., and Zúñiga, F. R.: Analysis of the ULF electromagnetic emission related to seismic activity, Teoloyucan geomagnetic station, 1998-2001, Nat. Hazards Earth Syst. Sci., 4, 679-684, doi:10.5194/nhess-4-679-2004, 2004.

Kotsarenko, A., Molchanov, O., Hayakawa, M., Koshevaya, S., Grimalsky, V., Pérez Enríquez, R., and López Cruz-Abeyro, J. A.: Investigation of ULF magnetic anomaly during Izu earthquake swarm and Miyakejima volcano eruption at summer 2000, Japan, Nat. Hazards Earth Syst. Sci., 5, 63-69, doi:10.5194/nhess-5-632005, 2005.

Kotsarenko, A., Pérez Enríquez, R., López Cruz-Abeyro, J. A., Koshevaya, S.,Grimalsky, V., Yutsis, V., and Kremenetsky, I.: ULF geomagnetic anomalies of possible seismogenic origin observed at Teoloyucan station, México, in 1999-2001: Interme- 
diate and Short-Time Analysis, Tectonophysics, 431, 249-262, doi:10.1016/j.tecto.2006.05.036, 2007.

Kushwah, V., Singh, V., and Singh, B.: Ultra low frequency (ULF) amplitude observed at Agra (India) and their association with regional earthquakes, Phys. Chem. Earth, 34, 367-272, 2009.

Molchanov, O. A. and Hayakawa, M.: Seismo-Electromagnetics and Related Phenomena, History and latest results, TERRAPUB, Tokyo, Japan, 189, 2008.

Parrot, M. and Johnston, M. J. S.: Seismoelectromagnetic effects, Phys. Earth Planet. Int., 57, 177, 1989.

Serita, A., Hattori, K., Yoshino, C., Hayakawa, M., and Isezaki, N.: Principal component analysis and singular spectrum analysis of ULF geomagnetic data associated with earthquakes, Nat. Hazards Earth Syst. Sci., 5, 685-689, doi:10.5194/nhess-5-685$2005,2005$.
Smirnova, N., Hayakawa, M., and Gotoh, K.: Precusory behavior of fractal characteristics of the ULF electromagnetic fields in seismic active zones before strong earthquakes, Phys. Chem. Earth, 29, 445-451, 2004.

Telesca, L. and Hattori, K.: Non-Uniform scaling behavior in ultralow-frequency (ULF) earthquake-ralated geomagnetic signals, Physica A, 384, 522-528, 2007.

Telesca, L., Lapenna, V., Macchiato, M., and Hattori, K.: Investigating non-uniform scaling behavior in Ultra Low Frequency (ULF) earthquake-related geomagnetic signals, Earth Planet. Sci. Lett., 268, 219-224, 2008. 